\title{
Tuning in to More Interactivity - Learning from IT Support for Advisory Service Encounters
}

\author{
Dolata, Mateusz ; Schwabe, Gerhard
}

\begin{abstract}
Advisory service encounters change their character from expertise provision to interactive problem solving, thus increasingly relying on mutual and intensive interaction between the advisor and the advisee: they turn into interactive advisory service encounters. Simultaneously, modern collaborative IT finds its way into service encounters as a method to engineer, enrich, and standardize them. An IT system equipped with interactive features may enhance the encounter's interactivity, but it may also limit it by capturing participants' attention. This study explores the influence of IT on the interactivity in advisory service encounters. It arrives at the conclusion that an extensive tuning in precedes a phase of enhanced interactivity in IT-supported advisory service encounters.
\end{abstract}

DOI: https://doi.org/10.1515/icom-2016-0042

Posted at the Zurich Open Repository and Archive, University of Zurich ZORA URL: https://doi.org/10.5167/uzh-138173

Journal Article

Published Version

Originally published at:

Dolata, Mateusz; Schwabe, Gerhard (2017). Tuning in to More Interactivity - Learning from IT Support for Advisory Service Encounters. i-com: Journal of Interactive Media, 16(1):23-34.

DOI: https://doi.org/10.1515/icom-2016-0042 


\section{Research Article}

\section{Mateusz Dolata* and Gerhard Schwabe}

\section{Tuning in to More Interactivity - Learning from IT Support for Advisory Service Encounters}

DOI 10.1515/icom-2016-0042

\begin{abstract}
Advisory service encounters change their character from expertise provision to interactive problem solving, thus increasingly relying on mutual and intensive interaction between the advisor and the advisee: they turn into interactive advisory service encounters. Simultaneously, modern collaborative IT finds its way into service encounters as a method to engineer, enrich, and standardize them. An IT system equipped with interactive features may enhance the encounter's interactivity, but it may also limit it by capturing participants' attention. This study explores the influence of IT on the interactivity in advisory service encounters. It arrives at the conclusion that an extensive tuning in precedes a phase of enhanced interactivity in ITsupported advisory service encounters.
\end{abstract}

Keywords: interactivity, advisory service encounter, financial advisory encounter, interactive problem solving

\section{Introduction}

Advisory service encounters are a wide-spread type of collaboration. They include patient-doctor or student-teacher counselling, as well as other forms of collaboration where an expert, i.e., advisor, provides advice on a predefined matter a layperson, i.e., advisee. In the era of instant information access, the role of advisory services has improved: whereas standard cases can be solved by the concerned persons based on the publicly available information, providing appropriate solutions in more complex and wicked situations requires expert knowledge and skills offered in form of advisory services. Consequently, the framing of advisory service encounters evolves from expertise provision to interactive problem solving - we propose the term interactive advisory service encounters (InterAdvise) to capture the new character of advisory encounters. By InterAdvise we mean an advisory service encounter which relies

*Corresponding author: Mateusz Dolata, University of Zurich, Department of Informatics, 8050 Zurich, Switzerland, e-mail: dolata@ifi.uzh.ch, http://orcid.org/0000-0002-2732-4465

Gerhard Schwabe, University of Zurich, Department of Informatics, 8050 Zurich, Switzerland, e-mail: schwabe@ifi.uzh.ch on mutual and interactive exchange between the advisor and the advisee and is oriented at rapport building and interactive problem solving, as opposite to one-sided information provision and selling. Because of this re-framing novel support tools and quality measures are necessary to enhance and assess advisory encounters.

Interactive problem solving requires both parties - the advisor and the advisee - to interact with each other when trying to understand the situation and elaborate a solution. In the face-to-face service encounters, interacting means, primarily, engaging in the mutual communication. Only if both partners establish an intensive mutual interaction, they can proceed with solving the problem. The concept of interactivity captures the intensity to which a two-way interaction is present in an encounter [43].

The evolution towards InterAdvise and the digitization of services require modern and dedicated collaborative IT systems to enhance and enrich the collaboration. On the one hand, IT equipped with interactive features and being an interactive medium can be expected to improve the interactivity of the whole encounter. On the other hand, IT may capture so many collaborative resources (time, attention, etc.) from the human participants, that the two-way dialogue will stagnate, thus reducing the encounter's interactivity. Because of the rapid changes, the role IT plays for the interactivity of modern interactive-problem-solving encounters remains underexplored. IT more and more finds its way into advisory service encounters in form of tablet-based mobile apps or other systems, e.g., at financial institutions, doctor's offices, and insurance companies. The velocity of changes will enhance in the years to come - in our opinion, it is the most appropriate, if not the last moment to ask fundamental yet necessary questions about the impact of IT on collaboration in advisory service encounters. Consequently, the current study explores the following research question:

RQ: Does IT enhance or lessen the interactivity of advisory service encounters?

The answer to this question shall provide effective guidance on the design of modern IT for advisory service encounters thus helping designers and practitioners in the field. We define IT support not only as a technological phe- 
nomenon but as technology along with the practices it affords. Consequently, linking IT to the interactive problem solving and, especially, to the concept of interactivity provides a new lens applicable in similar collaborative scenarios. We apply, present, and argue for an operationalization of interactivity which can be propagated in other research. We set our scope to financial service encounters, e.g., encounters that clients attend if they want to make a significant investment. This type of encounters shares a lot with other advisory services such as patientdoctor or supervisor-student encounters: First, in investment advisory service, there is much at stake including people's wealth. Second, mutual trust plays an important role in establishing a long-lasting relationship between the advisee and the advisor. Third, the interpersonal (hightouch) character of the session is shown to be more important for the advisor and the advisee $[28,40]$ than the technical and pragmatic issues (low-tech).

\section{Related Work}

The changes in the advisory service encounters have two sources: (1) the popularization of the Internet as the basic source of information and, consequently, retreat from face-to-face services to on-line service provision for standard cases; (2) the introduction of IT into face-to-face advisory service encounters as support tools, especially, for documentation and data processing purpose. This study focuses entirely on the effects of IT within a face-to-face encounter. The related work sets adequate focus while establishing the framing of advisory service encounters as InterAdvise, discussing current IT design efforts, and presenting the interactivity as a feature of service encounters.

\subsection{Advisory Encounters as Interactive Problem Solving}

The changes in the service provision essentially impact the character of face-to-face advisory service encounters, especially in finances. Earlier, opening a deposit required the client to visit the bank, which gave opportunity for discussion about new offerings, e.g., more lucrative saving and investment products. However, nowadays opening a deposit requires just few clicks in the online banking. The grow of online-only banks and the rise of FinTech [45] illustrate how new channels affected services in finances: opening an account, taking loans, and making investments is already possible from home and there is more to come. Consequently, the face-to-face advisory service encounters are evolving: as the "standard cases" move online, the clients who attend to face-to-face encounter bring a "special case" - one that they consider wicked or complex; one, where they know that they want something but do not know what actions to perform to get it [29]; one that is called a problem. This has influence on the advisors and their job: instead of processing many standard situations, they deal with specific problems, where they need to offer solutions that satisfy the client as well as the bank, the advisors' employer.

So far the financial advisory service encounters have been framed from the information exchange perspective. It views a financial advisory service encounter as an sequential or iterative arrangement of information collection, information provision, and recommendation [33]. Per this view, an advisory encounter should balance out the knowledge asymmetries between the partners and, thereby, enable for symmetric collaboration [18, 19, 30, 32]. More recent research from the area of non-commercial encounters indicates, however, that advisory encounters are in fact more like problem solving conducted in a collaborative manner [39]. While we agree with this perspective, it leaves several issues open: Under what circumstances is an advisory encounter an instantiation of problem solving? What are the features of problem solving as opposite to information exchange models? What role does interactivity play in problem solving? We propose the interactive problem solving as a perspective which allows to approach those questions.

Interactive problem solving (IPS) is a problem solving approach popularized in diplomacy and negotiation solving $[20,21]$. It has its origin in the notion of joint problem solving from the area of managerial decision taking and organizational conflict resolution [35, 42, 44]. The idea of joint search for solutions has attracted much attention in the diplomacy practice where it supplements the traditional and still official way of bargaining for concessions before declaring a compromise between the conflict parties [20]. It builds upon the assumption that conflicts are symptoms of problems - while it is possible to stove off the conflict through negotiation, solving the problems requires another approach [21]. First, IPS prescribes a joint identification of the desired state and the current state under consideration of causes and facts $[21,27]$ - thereby, the parties jointly identify the problem if they do not see an obvious way to reach a desired state. Second, the participants jointly shape various solutions for the problem and evaluate them $[21,27]$ - a solution describes the actions to be taken to reach the desired state. Third, the participants involve in positive and mutual enticement and reas- 
surance on the way to develop a precise action plan including action steps and potential snags [21, 27]. IPS requires a supportive environment, which is continuously established and reassured by the parties [21] - the supportive character comes to live with specific individual and group interaction behaviors [21, 27], which get expressed in gestures and verbal statements, i.e., in a smooth and interactive communication [21].

The modern financial advisory service encounters develop into IPS: Advisors are incentivized to establish mutual rapport and long-lasting relationships with the clients rather than selling individual products. Clients who attend advisory services are mostly in a new, possibly wicked situation, which may not fit into standard bank offering - they rather want to draw up an individualized solution which maps bank offering to their inquiry or addresses some of the fundamental issues rather than negotiate a concession. Importantly, each partner possesses relevant information: the advisee is the expert in the problem domain - she knows the situation and its limitation best; the advisor is the expert in the solution domain - he knows the range of available products and their flexibility. An InterAdvise offers a space to bring those knowledge sources together: From the very beginning, the advisor and the client engage in rapport-building behavior on a verbal and non-verbal level [12]. The advisee provides information she considers relevant for her case - the advisor establishes an early understanding of advisee's issue which allows to treat it as a problem [23], e.g., financial security in the future. To address this problem, the advisor provides general information on the range of possibly relevant offerings and teaches the client about the details and factors that describe a possible solution [13], e.g., investment and deposit products and their vulnerability to market conditions. When engaging with the matter, the client complements the previously provided information - be it selfinduced or as an answer to advisor's inquiry [23], e.g., her future professional aims. Simultaneously, some relevant offerings become increasingly specific and others get rejected as the advisee specifies her preferences or based on the advisor's assessment - a plan or plans emerge in form of actions to be taken so that the problem can be solved [15], e.g., an investment plan considering the professional aims. The encounter continues as a discussion of possible solutions, relevant differences and factors, specification of the plans, etc. The information coming from both parties enables for empathy and mutual enticement, such that the solution goes beyond a simple recommendation or negotiation. This means, that the financial advisory services research needs to question the underlying quality assurance models relying on the linear and ordered information ex- change $[18,19]$, and adapt a more flexible view as incorporating mutuality and interactivity [41]. Furthermore, it is essential to establish measurements, which capture the interactive and mutual character of InterAdvise.

\subsection{IT in Advisory Service Encounters}

Reframing advisory encounters into InterAdvise bears consequences for the design of the encounters, including simple brochures as well as IT systems. In fact, modern IT seems predestined for supporting IPS. Whereas the traditional encounter was built around the concept of an information provision and recommendation, InterAdvise relies on the concepts of problem and solution - it requires the problem and the solution to be established in a collaborative and supportive manner. In the traditional encounter IT was built to support the advisor at providing most appropriate recommendation - IT reduced the amount of time spend on calculations or bookings and had essential role in facilitating the documentation; normally, the system was visible only to the advisor who could turn the screen towards the advisee if he wanted so [2]. This type of systems still dominates in the field. However, recent studies on IT in service encounters focus increasingly on supporting collaboration - the systems presented in literature introduce effective help relying on such predicates as: (1) shared screen, (2) joint information spaces, (3) flexible and light-weight, non-rigid processes, (4) transfer of skills and understanding based on experience $[8,13,39]$. IT developed along those lines was shown to improve knowledge transfer, transparency, empowerment of the advisors and advisees, as well as their motivation to tackle the addressed issues [13, 32, 39]. It was also used to generate better visualizations and to streamline and standardize the experience across encounters [15]. Nevertheless, studies repeatedly report on the problems of such modern systems regarding the quality of communication [22, 40]. Depending on its features and usage scenario, IT may destroy entrance sequences in advisory encounters [34] or introduce hesitations and unnecessary repair sequences in implicit and explicit communication [22]. This reflects the basic dilemma of collaboration support [4]: IT has advantages in terms of process and product support, and enforces quality standards and practices, but bears great challenges if it comes to the quality of communication between people.

But it is exactly the smooth communication between the participants that is essential for IPS to happen. How is it possible that IT developed with collaboration in mind may in fact compromise on the quality of communication being so essential to mutual and supportive collaboration? 
Understanding the role of IT for the communication quality in collaborative situation is necessary and will remain an ever-open topic. With this study, we want to add a piece of knowledge that may help closing this gap.

\subsection{Interactivity in Advisory Service Encounters}

Successful problem solving in a collaborative situation depends strongly on the interactivity of the ongoing collaboration [41]. While interaction designates the action in which two or more objects have effect on each other, interactivity describes the quality and intensity of this action, i.e., of the relation between two objects or systems [25, 41]. Interactivity has been a widely-discussed topic and plays a central role in such areas as communication science, computer science, marketing and advertising just to mention a few [17]. There exist countless definitions of interactivity and all add a new perspective to this complex phenomenon [25]: (1) Some researchers focus on interactive features of media [24] or even single interfaces [1] and use interactivity as classification criterion for artifacts. (2) Others define interactivity as experiential measure, i.e., they define the interactivity of an experience through the self-reports of participants or users [6]. (3) Finally, there exist a range of definitions that derive interactivity from observable qualities of the actual interaction. In this category fall definitions using (3a) the message-based view, in which the interdependence between consecutive messages is considered as relevant [36], and (3b) the dialoguebased view that emphasize the conversational nature of interactions $[17,26]$. Following the latter view, an interactive encounter (3b-I) exhibits reduced time lags between the exchanges of the participants or objects [3] and (3b-II) makes the role of sender and recipient of a message easily interchangeable [37]. In other words, both conversation participants often take floor without additional lags between the verbal statements or actions.

This study follows the dialogue-based view on interactivity and uses a particular definition proposed by Johnson et al. [17] for several reasons: (1) we observe real, faceto-face communication framed as dialogue, (2) this view and the according definition attract more and more attention in the recent years, especially in the area service science, to approach the topic of novel service encounters, (3) the definition was designed to bridge the gap between technology- and human-oriented concepts of interactivity. Johnson et al. see the general interactivity as derivative from the non-mediated (behavioral) interaction and mediated (technology-based) interaction, which both result in an experience of interactivity. Johnson et al. account for reciprocity, responsiveness (being a specific form of reciprocity), nonverbal behavior, and speed of response as dimensions that define interactivity in all interactions.

Reciprocity is widely acknowledged in the interactivity literature and is put on a par with "dialogue", "participate", "iterative", "two-way communication", "actions and reactions", and "talking back" (cf. [17], for further references). In a reciprocal exchange, participants engage in a more balanced communication where they alternately play the role of sender and receiver, as opposite to a monologue with a single dominating part. If messages in an exchange build content wise upon each other, we talk about responsiveness. Speed of response refers to the extent to which messages in an exchange occur in real time or with delay. A minimum delay contributes to the continuity of the exchange, but delayed responses, signalized by breaks and pauses, hinder communication flows, lead to information losses, and reduce the overall interactivity of the exchange [17]. Also, the definitions mentioned earlier (3b-I and II) stress the role of reciprocity and speed of response, as central and most settled ones within the dialogue-based conceptualization of interactivity.

Importantly, establishing a smooth verbal communication, including easy role-switching in a balanced and breakdown-free manner, i.e., with high reciprocity and speed of response, requires a preparatory phase. This early phase has been described as tuning-in relationship. It originates from music and denotes the process at the beginning of an improvisation: the participants involve in a process of synchronizing their inner time with the group - they tune in [38]. In doing so, they establish a single rhythmic structure. The analogy is adapted by Gregory and Hoyt [10] to describe the mutual adjustment of communication partners.

Overall, the current study leverages the notion of interactivity presented above to describe the influence of modern IT support for advisory encounters on those encounters. The current changes in the market and service provision turn traditional information-exchange advisory encounters into InterAdvise. This requires engagement and intensive interaction between the advisor and the advisee to enable for a supportive environment as well as mutual enticement and reassurance practices to emerge, which are essential to IPS. However, IT systems developed along the lines of problem solving and, especially, the processual dimension of IPS were reported to compromise exactly on the human interaction. The available studies focus on single breakdown episodes and miss to point to the larger dimensions of communication that get affected $[22,28]$ and do not explain the problems in terms of com- 

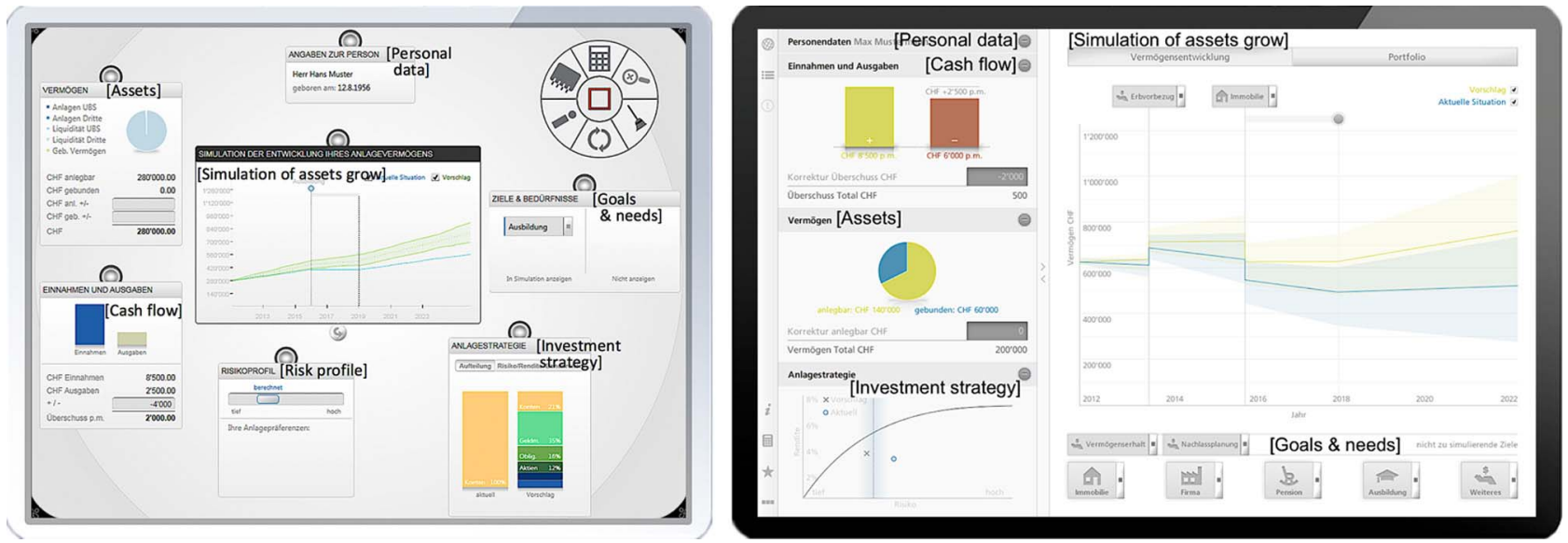

Figure 1: Design of the prototypes - Left: Touch Table deployed on a 30-inch touch display. Right: Tablet prototype on a 10-inch touch display.

munication mechanisms, but reduce them to usability issues [12, 34]. This paper explores the impact of modern IT systems on the interactivity in the advisory service encounters in terms of repetitive patterns and describes a general communication mechanism that explains the observations.

\section{Methodology}

To answer the research question, we conduct secondary data analysis [7] of 18 videos of realistic advisory session from two identically designed within-subject experiments with a major Swiss bank [31]. The experimental advisory sessions were conducted with a group of real retail-sector financial advisors and test advisees who were acquired through convenience sampling by postings on a university job marketplace. The test advisees were paid approx. 50 EUR (instructions of the local psychology department) for their participation of overall three hours including running through IT and non-IT conditions. Before the tests, the advisees received a 15-minute introduction, a hypothetical financial profile, and a scenario to follow. They should receive an advice on investing a given amount of money (up to 250'000 EUR), while considering a financial need (e.g., buying a car). The advisors were trained to use the introduced tool a few days in advance and additionally at the day of the experiment. They were aware of all the functionalities, the system provides, and had several options to try it out before the experiment. The considered videos come from three treatments (6 videos from each): (A) No IT - service conducted without no IT but with pen and paper, as usually in this bank, (B) Tablet - service conducted with use of a prototype deployed on a 10-inch tablet computer, (C) Touch Table - service conducted with use of a prototype deployed on a multi-touch tabletop device with a 30-inch flat display.

The systems used in this research were developed in a user-centered design science research [14] project with the goal of improving transparency in financial advisory encounters [31]. The Tablet and the Touch Table systems were designed in accordance with the state-of-the-art design principles and proven to exhibit the same level of usability as the pen-and-paper setting [31]. The prototypes implement the following features: shared information screen, "at one sight"-overview, flexible handling without explicated process steps, and personalization of information and visualizations ([31]; Figure 1). The Touch Table prototype uses the idea of widget as main design element as follows: (1) the particular widgets (e.g., "assets" or "personal data") are by default distributed across the available space and provide modular functionality used during the advisory session, (2) the widgets are interconnected such that information change in one widget (e.g., income in "cash flow") influences information presented elsewhere (e.g., in the "simulation of assets grow"), (3) all widgets are visible at all times, can be replaced and zoomed-in to present more specific information. The Tablet prototype uses the same visualizations and algorithms, but - due to space limitations - reinterprets the widget metaphor as follows: (1) the widgets are placed next to each other and take the whole available space, (2) some widgets must first be opened by a click on the title to show their content (e.g., "personal data" in Figure 1, right) (3) the widgets can be moved only in the predefined areas, e.g. in the upper right corner for zoom-in (e.g., in Figure 1, right, the widget "simulation of assets grow" is zoomed-in) or in the left panel for zoom-out (e.g., "assets"), (4) the logics and intercon- 
nection between widgets is the same as in the Touch Table prototype. Nussbaumer [31] provides an exact description of the prototypes and the development process thereof. This study uses the systems solely as vehicles to observe influence of a dedicated IT on the interactivity.

To counterbalance the order effects, we randomly assigned the advisees to start with either an IT-supported or conventional condition. Each session took approximately 30 minutes. The video footage was coded with ELAN [5]. Two assistants coded the following layers: verbal activity of advisor and advisee, usage of tools, and further notes. High inter-rater agreement and reliability on a sample of eight five-minute segments assure the data quality (agreement: Cronbach's $\alpha=0.866$; reliability: ICC $=0.765$; cf. [11]).

All patterns reported in the subsequent chapter use the notion of a time segment. To observe dominating trends in communication, each advisory session was divided in five equal time segments. All measurements (advisees' and advisors' amount of talk, pauses) are then aggregated for each time segment. We present trend graphs using averaged numbers of all videos. The length of time segments (approx. 6 minutes) is chosen deliberately: it is longer than a statistical cyclic turn but shorter than any predefined stages of the advisory service. In our results, we report on the verbal activity of the participants: (1) First, we consider patterns of silence, defined as moments when no one speaks. In this analysis, we only consider pauses longer than 1300 milliseconds, thus above the standard silence metric proposed in the literature [16]. We ignore silence moments occurring clearly due to the usage of the tools, as well as occurring during "technical breaks", i.e., we retain only unfilled pauses. The higher the number of unfilled pauses, the lower the speed of response, and consequently the lower the interactivity. (2) Second, we make observations on the amount of talk in the single time seg- ments. This enables for identification of a speakers' dominance in the phases. If one of the speakers clearly dominates the stage and takes much floor in his or her turns, the participation of the other collaboration partner naturally reduces, thus leading to reduced reciprocity, and consequently to a lower interactivity of collaboration. In addition to reporting on the above measures, we calculate their average amplitudes: For each video, we compute the difference between phases with the highest and the lowest values of the variable to obtain the video's specific amplitude. Amplitudes show how volatile the given variable is if observed across the time segments and videos. If taken together with the provided trends in communication, they illustrate whether a participant tends to dominate or be submissive in a single phase.

\section{Results}

The results deal with the amount of talk to show effects of IT on reciprocity in communication, as well as unfilled pauses to illustrate effects on the speed of response.

As depicted in Figure 2 (left), advisee's amount of talk in all three conditions is rather low and oscillates on average around $20 \%$ of the overall duration of the advice. In the IT conditions, the variances are small, but we observe a considerable drop between second and fourth time segment in the No IT condition. This is reflected in amplitudes computations (Figure 2, right). The No IT condition exhibits significantly higher amplitudes than the IT conditions (A vs. $B: p=.006, t=4.484, d f=5.000$; A vs. C: $p=.007, t=3.382, d f=10.000$ ), while there is no difference between the IT conditions.

Complementary trends occur in advisor's amount of talk which oscillates around 70\%-90\% (Figure 3). This reflects the strong domination of the advisor in all settings.
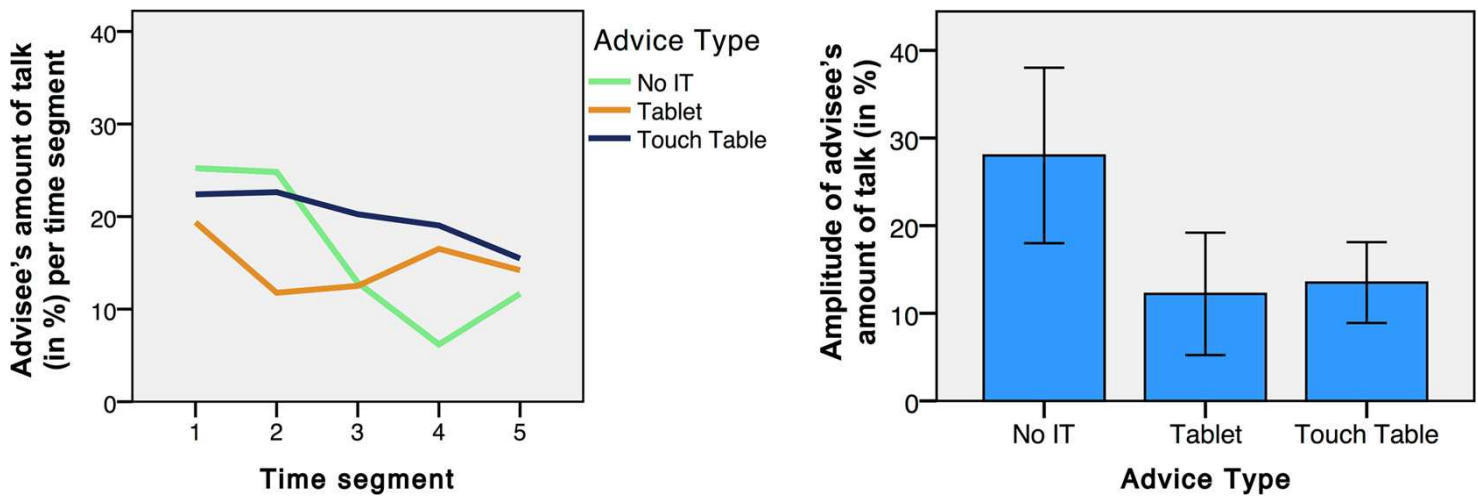

Figure 2: Left: Trends in advisee's amount of talk throughout the session. Right: Averaged amplitudes of advisee's amount of talk (error bars: $95 \% \mathrm{Cl}$ ). 

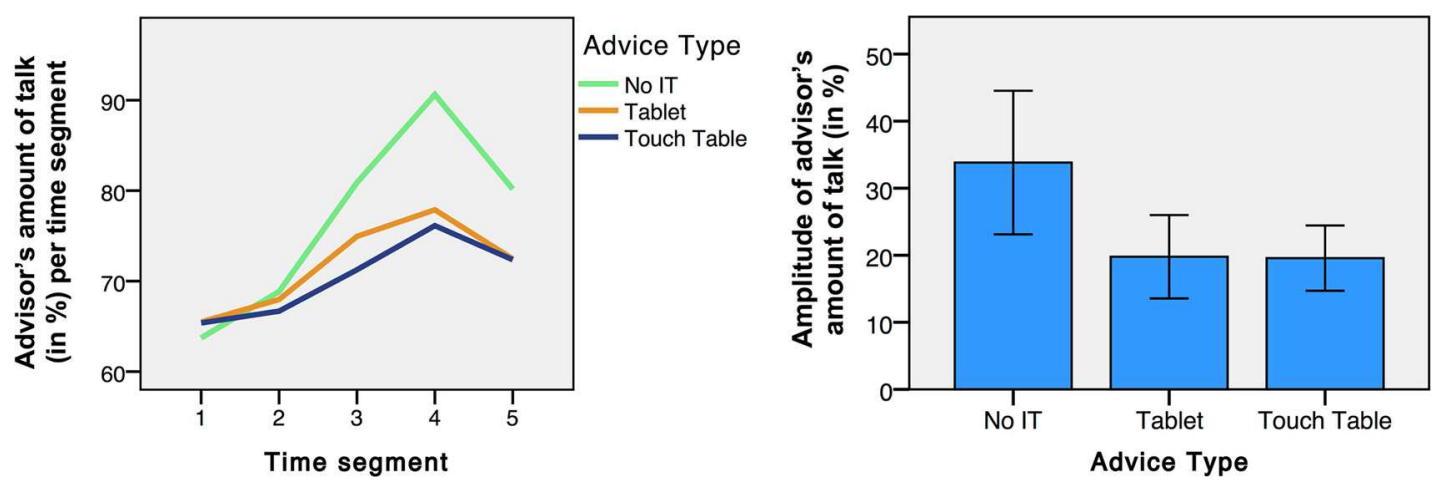

Figure 3: Left: Trends in advisor's amount of talk throughout the session. Right: Averaged amplitudes of advisor's amount of talk (error bars: $95 \% \mathrm{Cl})$.
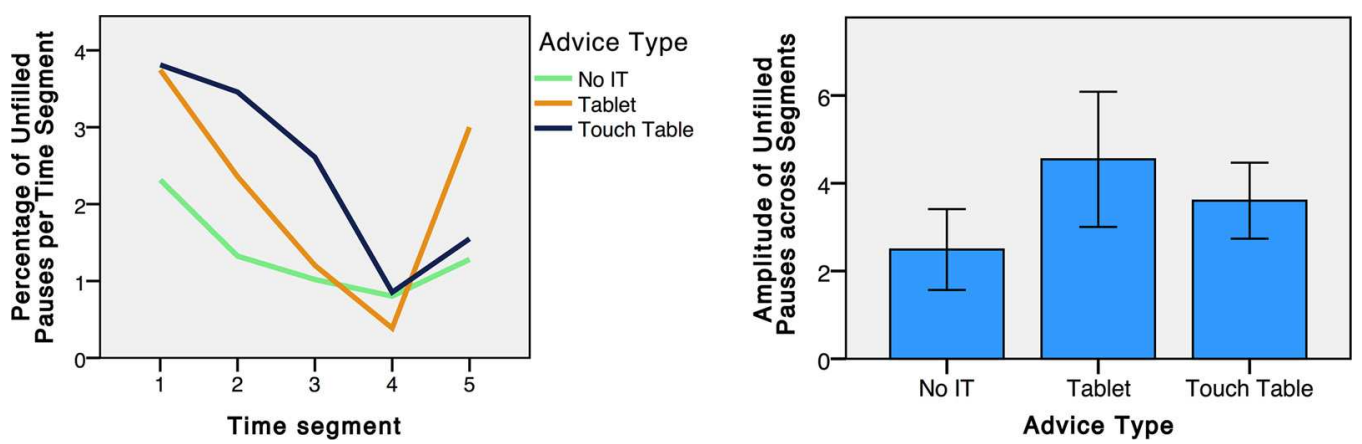

Figure 4: Left: Trends in occurrence of unfilled pauses throughout the advisory session. Right: Averaged amplitudes of number of unfilled pauses (error bars: $95 \% \mathrm{Cl}$ ).

Interestingly, in each condition, the trend line reaches its high in the second last time segment. In the No IT case, this growth is twice as high as in the IT cases as illustrated by the average amplitude (A vs. B: $\mathrm{p}=.05, \mathrm{t}=2.552, \mathrm{df}=5$; A vs. $\mathrm{C}: \mathrm{p}=.017, \mathrm{t}=3.115, \mathrm{df}=6.983$; cf. Figure 3 , right).

The observations we make on silence (cf. Figure 4) add to the picture. Clearly, in each condition unfilled pauses occur more often in the early phase while getting less towards the end. Particularly, in the fourth time segment all conditions reach the same, very low, level of mutual silencing. Interestingly, at the beginning of the advisor session silence occupies in the IT conditions approx. $4 \%$ of the overall time, whereas in the No IT case it reaches $2 \%$. Reported fluctuations reflected by the amplitudes of unfilled pauses across time segments (A vs. $\mathrm{B}: \mathrm{p}=.006, \mathrm{t}=-4.516$, $\mathrm{df}=5$; A vs. $\mathrm{C}: \mathrm{p}=.047, \mathrm{t}=-2.264, \mathrm{df}=10$; cf. Figure 4, right).

\section{Discussion and Conclusion}

The above results point to the fact, that the IT-prototypes introduced into the InterAdvise have essential impact on the speed of response and on the reciprocity of interaction. Previous literature either criticized IT for disturbing communication in advisory encounters while describing particular episodes [22], pointed to bad usability design as the crucial negative factor [34], or defined design factors as essential for enabling positive work and communication practices [13], this study makes clear that a better picture emerges if the observed patterns are put in relation with communication mechanisms and holistic features of interaction such as its interactivity. This section, first, elaborates the relationship between IT and interactivity in the advisory service encounters in more detail, and, second, discusses what it means to design for InterAdvise.

\subsection{Interactivity and IT in Advisory Service Encounters}

Coming back to the question whether IT enhances or lessens an advisory encounter's interactivity, the above results provide a complex but consistent picture: the interactivity in IT-supported encounters suffers from lower speed of response in the early phases, but benefits from higher 
Table 1: Summary of the results on the influence of IT on interactivity in advisory encounters.

\begin{tabular}{lll}
\hline & Early phase & Late phase \\
\hline Speed of response & IT $<$ No IT & IT $\approx$ No IT \\
Reciprocity & IT $\approx$ No IT & IT $>$ No IT \\
\hline Interactivity & IT $<$ No IT & IT $>$ No IT \\
\hline
\end{tabular}

reciprocity later. Table 1 summarizes this insight: (1) Regarding the speed of response - operationalized by the distribution of unfilled pauses - the early time segments of IT-supported encounters exhibit substantially less speed of response (more unfilled pauses) than the No IT case. In the later phase, the speed of response is comparable across the conditions. (2) Regarding the reciprocity - operationalized by the advisor's and advisee's amount of talk - all conditions exhibit similar patterns in the early phase of the encounter. However, later, the advisor's dominance over the advisee grows and is substantially higher in the No IT condition than in the other ones. When the advisor takes $90 \%$ of the floor and leaves less than $10 \%$ to the advisee (i.e., just every tenth word is by the advisee) the chance of a reciprocal exchange is low. In the IT conditions this ratio changes for better: the advisee can take $20 \%$ of the floor (i.e., she contributes every fifth word). Overall, the above analysis shows that IT impedes the interactivity in the early phases of the encounter, thus making the joint problem solving [39] difficult, but later it improves the interactivity defined as a dialogue-based feature $[25,3,37]$.

The results point to dimension of time in the sense of duration of the advisory service as the crucial factor to be considered before deciding on whether IT has positive or negative impact on the encounter. We argue, it shall be included in the discussion on what challenges and opportunities are brought with inclusion of novel IT into service encounters. While in the early collaboration phase, the presence of collaborative IT generates additional challenge for the interpersonal communication, the observation in the later phases show that IT also bears additional potential to improve the interactivity and consequently the collaboration quality. The tuning-in relationship [10] provides an explanation to the observed patterns. While extending this metaphor, we argue that the IT tool in the encounter is an additional instrument added to the standard situation. In the early phases, the tuning in simply takes more time, thus the speed of response drops. As time goes by and the mutual adjustment progresses, hesitations diminish and a novel configuration and positioning is possible, i.e., novel patterns of communication emerge - ones that offer possibilities for more reciprocity. In other words, instead of two soloists in the ensemble, through introduction of an interactive IT tool, we get a trio. Consequently, the dyadic model of dominance and submission evolves and opens space for new patterns. This explanation sheds new light on the negative influence of IT on interpersonal communication in advisory settings reported earlier [34, 22].

Consequently, we postulate to include time dimension into the design and use of collaborative systems, especially for the advisory scenario. Introducing IT which gets used only for a short time may, in fact, have negative effects on the interpersonal communication that outstrip any positive effect of IT. However, if the IT gets used for longer than the early stages of the advisory service, it will unveil its positive effect and support more interactive exchange. For instance, it may be necessary to consider redesign of service encounters to allow for appropriate tuning in in the early phases, i.e., specific behavioral scripts (e.g., ThinkLets - [4]) or set of restrictions need to be put in place to support effective tuning in.

\subsection{IT-supported Interactive Advisory Service Encounters}

Given the evolution of service encounters and the definition of InterAdvise, we postulate that any changes and redesign of advisory services shall consider their increasingly interactive character. Specifically, the design of dedicated IT needs to move away from the information exchange models [18, 19, 33]. Instead, designing for interactive problem solving $[20,21,27]$ bears more potential and is likely to produce IT which will survive the currently ongoing evolution of advisory service encounters and gets finally adopted in practice as opposite to systems proposed earlier [28, 40]. Such IT will primary support collaboration between the parties understood as joint specification of the problem and common definition of actions necessary to tackle the problem. It will allow for emergence of mutual rapport and reassurance through signalizing the benefits of jointly elaborated solution for the client and for the bank [27]. Finally, it will form an invitation for the advisee to interact with the advisor and with the system itself.

Whereas the redesign of service encounter, including IT developed for use in advisory service encounters, has so far approached such topics as knowledge transfer [13], transparency [32], and empowerment [9], this study points to less invasive measurements. Measuring the intensity of verbal interaction can be easily done without the neces- 
sity to assess the service based on surveys or other standard evaluation methods. In fact, IT can be even used to automatically collect data on advisor's and advisee's verbal activity and compare it against various baselines. This opens new possibilities for the evaluation of real advisory services conducted in banks. Monitoring whether the clients interact with the advisors and how the advisors go about their dominating position may provide interesting data for the management in the financial institutions. Finally, monitoring the interactivity of the encounters may provide essential information on the performance of support systems and procedures introduced in the encounter: Are they in line with the evolution towards InterAdvise or do they push the advisee back to the position of a supplicant and the advisor back to the position of information provider?

\subsection{Limitations and Outlook}

This paper is the first to show how modern and dedicated IT for advisory services can improve the quality of verbal communication between the advisor and the advisee. It confirms the essential role that adaption of communication practices plays for the appropriation of collaborative software in co-located meetings. The lens, we propose in this paper, points to specific problems undetectable with other methods traditionally employed in evaluation of novel designs, such as the technology acceptance model and related measure instruments. At the same time, the limitations of the current study result from the choice of interactivity as the theoretical lens: the variety of definitions of interactivity available in the psychology and communication studies. The simplistic notion chosen for this paper does not capture the meaning of various non-verbal and verbal signs, but focuses solely on their presence: it makes the method easily applicable and reproducible, but also vulnerable to oversimplifications regarding the complex nature of face-to-face communication. Consequently, the observations need backing from the theory of communication (e.g., tuning in). Furthermore, we use realistic but still experimental recordings to conduct the analysis - obtaining recordings from real advisory sessions is difficult due to privacy reasons and confidentiality rules for financial institutions. Consequently, we encourage scientists to replicate the study in a real context, with real clients or with other IT support systems.

While the current research took the first explorative step towards understanding the role of interactivity in service encounters and proposed the notion of InterAdvise, it points to further potential in this area. The results pre- sented in here suggest the importance of this perspective for further design and research. Designers of dedicated IT for service encounters benefit from better view on the between the problem-solving character of such encounters and the character of interpersonal communication. Furthermore, they may consider the concept of tuning in helpful for leveraging the early phases of the encounter and streamlining the later ones, so that the participants can focus on problem solving once they are tuned in. Researchers around collaborative systems benefit from the new, interactivity-oriented perspective on collaboration including the adaptation and operationalization of the dialogue-based view on interactivity for observing interpersonal processes in collaboration. Additionally, they may find it attractive to follow up on the research path proposed in here, which leaves the - so far more popular - interactivity concepts focused on technology or selfperception. Consequently, we ask: Can one observe similar interactivity patterns in other scenarios than advisory services? How should we design IT systems to reduce the tuning in to the minimum? How does tuning in in collaborative setting differ from adapting to a new system in an individual usage scenario?

\section{References}

[1] Albert, T. C., Goes, P. B., and Gupta, A. 2004. "GIST: a model for design and management of content and interactivity of customer-centric web sites," MIS Quarterly, pp. 161-182.

[2] Arvola, M. 2004. Shades of use: the dynamics of interaction design for sociable use, Linköping studies in science and technology. Dissertation, Linköping Univ.

[3] Bretz, R. 1983. Media for interactive communication (M. Schmidbauer, ed.), Beverly Hills, CA, USA: Sage Publications.

[4] Briggs, R. O., Kolfschoten, G. L., de Vreede, G.-J., Lukosch, S., and Albrecht, C. C. 2013. "Facilitator-in-a-Box: Process Support Applications to Help Practitioners Realize the Potential of Collaboration Technology," Journal of Management Information Systems (29:4), pp. 159-194.

[5] Brugman, H., and Russel, A. 2004. "Annotating Multi-media/Multi-modal Resources with ELAN," in Proc. Intl. Conf. Language Resources and Evaluation.

[6] Burgoon, J. K., Bonito, J. A., Bengtsson, B., Ramjrez, J., Dunbar, N. E., and Miczo, N. 1999. "Testing the Interactivity Model: Communication Processes, Partner Assessments, and the Quality of Collaborative Work," Journal of Management Information Systems (16:3), pp. 33-56.

[7] Dolata, M., Kilic, M., and Schwabe, G. 2015. “Unpacking the Artifact Knowledge: Secondary Data Analysis in Design Science Research," in New Horizons in Design Science: Broadening the Research Agenda, Springer, pp. 327-342 (doi: 10.1007/978-3-319-18714-3_21). 
[8] Dolata, M., Comes, T., Schenk, B., and Schwabe, G. 2016. "Persuasive Practices: Learning from Home Security Advisory Services," in Proc. Intl. Conf. Persuasive Technology. LNCS, Springer International Publishing, April 5, pp. 176-188.

[9] Giesbrecht, T., Schwabe, G., and Schenk, B. 2016. "Service encounter thinklets: how to empower service agents to put value co-creation into practice," Information Systems Journal.

[10] Gregory, S. W., and Hoyt, B. R. 1982. "Conversation partner mutual adaptation as demonstrated by Fourier series analysis," Journal of Psycholinguistic Research (11:1), pp. 35-46.

[11] Gwet, K. L. 2012. Handbook of inter-rater reliability: the definitive guide to measuring the extent of agreement among raters, Gaithersburg, MD: Advanced Analytics, LLC.

[12] Heinrich, P., Kilic, M., Aschoff, F.-R., and Schwabe, G. 2014. "Enabling relationship building in tabletop-supported advisory settings," in Proc. Conf. Computer Supported Cooperative Work and Social Computing, ACM Press, pp. 171-183.

[13] Heinrich, P., Kilic, M., and Schwabe, G. 2014. "Microworlds as the locus of consumer education in financial advisory services," in Proc. Intl. Conf. on Information Systems.

[14] Hevner, A., and Chatterjee, S. 2010. "Design Science Research in Information Systems," in Design Research in Information Systems (Vol. 22), Boston, MA: Springer US, pp. 9-22.

[15] Heyman, S., and Artman, H. 2015. “Computer Support for Financial Advisors and Their Clients: Co-creating an Investment Plan," in Proc. Conf. Computer Supported Cooperative Work and Social Computing, New York, NY, USA: ACM, pp. 1313-1323.

[16] Jefferson, G. 1989. "Notes on a possible metric which provides for a 'standard maximum' silence of approximately one second in conversation," in Conversation: An interdisciplinary perspective. Multilingual Matters, Clevedon, UK.

[17] Johnson, G. J., Bruner II, G. C., and Kumar, A. 2006. "Interactivity and its Facets Revisited: Theory and Empirical Test," Journal of Advertising (35:4), pp. 35-52.

[18] Jungermann, H. 1999. "Advice giving and taking," in Proc. Hawaii Intl. Conf. System Sciences, Hawaii, US.

[19] Jungermann, H., and Fischer, K. 2005. "Using expertise and experience for giving and taking advice," The routines of decision making, pp. 157-173.

[20] Kelman, H. C. 1990. "Interactive problem-solving: A social-psychological approach to conflict resolution," in Conflict: Readings in management and resolution, Springer, pp. 199-215.

[21] Kelman, H. C. 1996. "Negotiation as interactive problem solving," International Negotiation (1:1), pp. 99-123.

[22] Kilic, M., Dolata, M., and Schwabe, G. 2016. "How IT-Artifacts Disturb Advice Giving - Insights from Analyzing Implicit Communication," in Proc. Hawaii Intl. Conf. System Sciences, Kauai, HI, US.

[23] Kilic, M., Dolata, M., and Schwabe, G. 2017. "Why do you ask all those questions? Supporting client profiling in financial service encounters," in Proc. Hawaii Intl. Conf. System Sciences, Waikoloa Beach, HI, USA.

[24] Markus, M. L. 1987. “Toward a 'Critical Mass' Theory of Interactive Media Universal Access, Interdependence and Diffusion," Communication Research (14:5), pp. 491-511.
[25] McMillan, S. 2005. "Exploring models of interactivity from multiple research traditions: users, documents and systems," in Handbook of new media (Vol. 2), pp. 205-229.

[26] McMillan, S. J. 2000. "Interactivity Is in the Eye of the Beholder: Function," in Proc. Conf. Amer. Academy of Advertising, East Lansing, MI, USA.

[27] Misselhorn, H. 1978. "Joint problem solving: Building better relationships and better solutions," Industrial and Commercial Training (10:2), pp. 60-70.

[28] Mogicato, R., Schwabe, G., Nussbaumer, P., Stehli, E., and Eberhard, M. 2009. "Beratungsqualität in Banken. Was der kunde erwartet. Was der Kunde erlebt.” Solutions Providers AG, Dübendorf, Switzerland.

[29] Newell, A., and Simon, H. A. 1972. Human problem solving (Vol. 104), Englewood Cliffs, NJ: Prentice-Hall.

[30] Novak, J. 2009. “Mine, Yours... Ours? Designing for principal-agent collaboration in interactive value creation," in Proc. Conf. Wirtschaftsinformatik, Vienna, Austria.

[31] Nussbaumer, P. 2012. "Essays on transparent IT support for asymmetric client-advisor encounters," Dissertation, University of Zurich.

[32] Nussbaumer, P., Matter, I., and Schwabe, G. 2012. “'Enforced' vs. 'Casual' Transparency - Findings from IT-Supported Financial Advisory Encounters,” ACM Trans. Management Information Systems (3:2), pp. 11:1-11:19.

[33] Oehler, A., and Kohlert, D. 2009. "Financial Advice Giving and Taking-Where are the Market's Self-healing Powers and a Functioning Legal Framework When We Need Them?," Journal of Consumer Policy (32:2), pp. 91-116.

[34] Pearce, C., Trumble, S., Arnold, M., Dwan, K., and Phillips, C. 2008. "Computers in the new consultation: within the first minute," Family Practice (25:3), pp. 202-208.

[35] Pondy, L. R. 1967. "Organizational Conflict: Concepts and Models," Administrative Science Quarterly (12:2), pp. 296-320 (doi: 10.2307/2391553).

[36] Rafaeli, S., and Ariel, Y. 2007. "Assessing interactivity in computer-mediated," in Oxford Handbook of Internet Psychology, p. 71.

[37] Rice, R. E. 1984. "New media and technology: growth and integration," in The New media: communication, research, and technology, Beverly Hills: Sage Publications.

[38] Schütz, A. 1951. "Making music together: A study in social relationship," Social Research, pp. 76-97.

[39] Schwabe, G., Briggs, R. O., and Giesbrecht, T. 2016. "Advancing Collaboration Engineering: New ThinkLets for Dyadic Problem Solving and an Application for Mobile Advisory Services," in Hawaii Intl. Conf. System Sciences, Kauai, HI, US, pp. 787-796.

[40] Schwabe, G., and Nussbaumer, P. 2009. "Why information technology is not being used for financial advisory," in Proc. European Conf. on Information Systems.

[41] Steffensen, S. V. 2013. "Human interactivity: problem-solving, solution-probing and verbal patterns in the wild," in Cognition beyond the brain, Springer, pp. 195-221 (doi: 10.1007/978-1-4471-5125-8_11).

[42] Swinth, R. L. 1971. “Organizational Joint Problem-Solving," Management Science (18:2), pp. B-68 (doi: 10.1287/mnsc. 18.2.B68). 
[43] Torres, F. A. 1995. Towards a universal theory of media interactivity: developing a proper context, Fullerton: California State University.

[44] Zand, D. E. 1972. "Trust and Managerial Problem Solving," Administrative Science Quarterly (17:2), pp. 229-239.

[45] Zavolokina, L., Dolata, M., and Schwabe, G. 2016. "FinTech-What's in a Name?" in Proc. Intl. Conf. Information Systems, Dublin, Ireland: AIS.

\section{Bionotes}

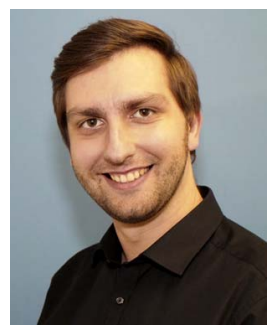

\author{
Mateusz Dolata \\ University of Zurich, Switzerland \\ dolata@ifi.uzh.ch
}

Mateusz Dolata is a Ph.D. student in Information Systems at the University of Zurich. In his research on the role of IT in face-to-face collaboration, he combines discourse analysis, conversation analysis, and multimodal analysis - he adapts methods from the communication science and linguistics to IS and CSCW. He focuses on the study of dyads and small groups in creative and interactive problem solving. In this context, he has studied conversational practices and patterns in IT-supported financial advisory encounters and in home security advisory encounters. Mateusz Dolata published the results of his studies at relevant conferences (ECIS, HICSS, DESRIST) as well as book chapters and journals.

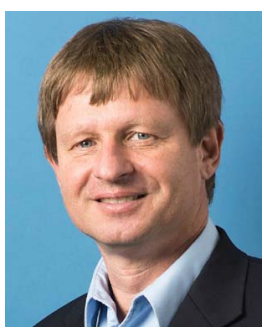

\section{Gerhard Schwabe}

University of Zurich, Switzerland

schwabe@ifi.uzh.ch

Gerhard Schwabe is a professor in the Department of Informatics, University of Zurich, where he leads the Information Management Research Group. He researches the intersection of collaborative technologies and information management. He has studied collaboration in commercial and government organizations at the granularity of dyads, small teams, large teams, organizations, communities, and social networks, frequently in collaboration with companies and public organizations. The topic of IT-supported advisory encounters is of special interest to him: since 2004 he has engaged in multiple projects with financial institutions, travel agencies, police, and communes in Germany and Switzerland where he studied the interaction between advisors, advisees, and computer - he published the relevant results at renowned conferences (ICIS, ECIS, CSCW, HICSS) as well as in a variety of journals (JMIS, IS), TMIS, Electronic Markets). 